\title{
Lesión traumática en carótida primitiva izquierda: de la sospecha al diagnóstico
}

Resi Silvana

Herrasti Marcelo

\section{Correspondencia}

Resi Silvana

silvanaresi@yahoo.com.ar

Instituto Cardiovascular Buenos Aires, Argentina

Recibido: 10/10/2021

Aceptado: 13/10/2021

En línea: 15/12/2021

Citar como: Resi S., Herrasti M.: Lesión traumática en carótida primitiva izquierda: de la sospecha al diagnóstico. RETIC. 2021 (Diciembre); 4 (3): 53-55. doi: 10.37615/ retic.v4n3a15

Cite this as: Resi S., Herrasti M.: Traumatic injury of left common carotid artery: From suspicion to diagnosis. RETIC. 2021(December); 4 (3): 53-55. doi: 10.37615/retic. v4n3a15

\begin{tabular}{l} 
Palabras clave \\
\hline$\triangleright$ Disección carotidea. \\
$\triangleright$ Lesión traumática cuello. \\
$\triangleright$ Enfermedad carotidea. \\
\hline Keywords \\
$\triangleright$ Carotid dissection \\
$\triangleright$ Neck traumatic lesion \\
$\triangleright$ Carotid disease \\
\hline
\end{tabular}

\section{Presentación del caso}

Varón de 31 años sin factores de riesgo cardiovascular. Consulta al servicio de emergencias por dolor localizado a nivel de músculo esternocleidomastoideo izquierdo que no cede con analgésicos de 5 días de evolución. Como antecedentes, refiere haber cargado con el hombro izquierdo una bolsa de $10 \mathrm{~kg}$ de tierra, mientras realizaba tareas de jardinería. Al ingreso a la sala de emergencias el examen físico cardiovascular y neurológico fue normal. Se realizó un estudio de Doppler Arterial de Vasos de Cuello (DAVC) que evidenció a nivel del tercio medio de carótida primitiva izquierda imagen hipoecogénica heterogénea que rodeaba el vaso en forma de semiluna por fuera de la capa íntima; compatible con hematoma intramural. El análisis de la onda espectral mostró un flujo anterógrado laminar con velocidades dentro de límites normales (Figuras 1A, 1B, 1C). Se realizó una Angiotomografía Multislice de Vasos de Cuello (VC) (Figuras 2A y 2B) que evidenció a nivel de tercio medio y distal de carótida primitiva izquierda asimetría del calibre con disminución del del mismo con respecto a la contralateral, sin estenosis significativa con obliteración de los planos grasos adyacentes en forma concéntrica. Se solicitó Angioresonancia de VC (Figura 3) para una mejor caracterización tisular de la lesión. Se decidió realizar tratamiento médico con antiplaquetario y tras 3 días de estabilidad clínica y de imagen guiada por el DAVC, se otorga el alta sanatorial. Se realizó control ambulatorio clínico y de imagen con DAVC al mes y a los dos meses evidenciándose regresión completa de la lesión (Figuras 4A y 4B).

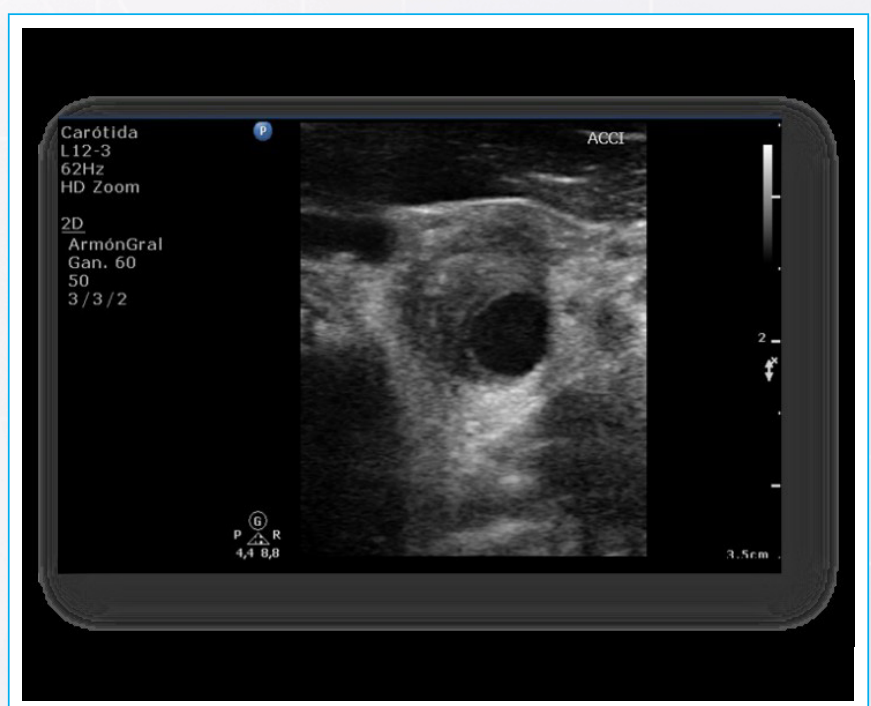

Figura 1A. Doppler Arterial de Vasos de cuello: Se observó a nivel del tercio medio de carótida primitiva izquierda imagen hipoecogénica heterogénea que rodea al vaso en forma de semiluna por fuera de la capa íntima compatible con hematoma intramural; el análisis de la onda espectral mostró un flujo anterógrado laminar con velocidades dentro de límites normales. 


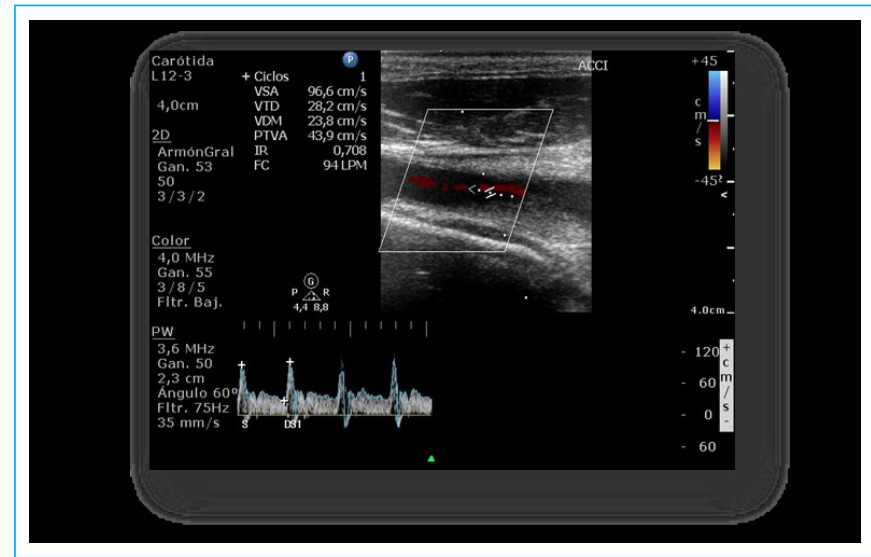

Figura 1B. Doppler Arterial de Vasos de cuello: el análisis de la onda espectral mostró un flujo anterógrado laminar con velocidades dentro de límites normales.

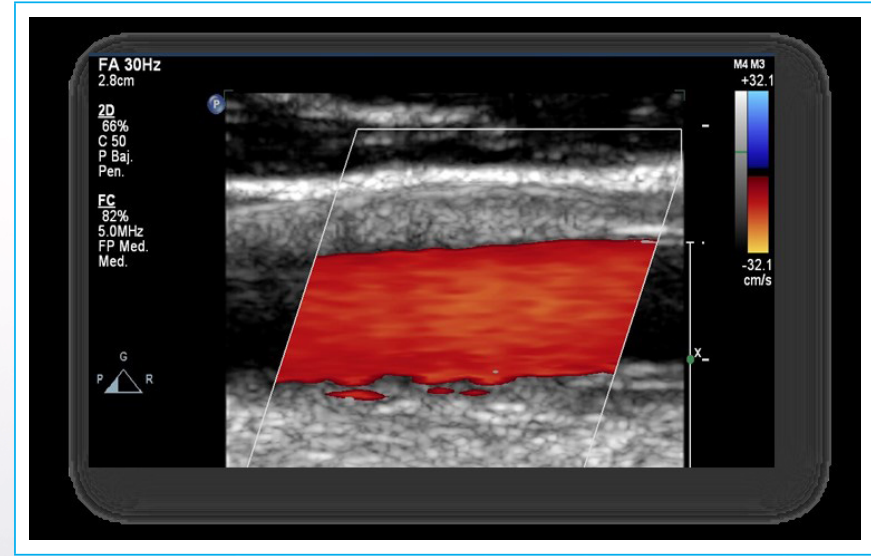

Figura 1C. Doppler Arterial de Vasos de cuello: Doppler color que muestra flujo laminar.

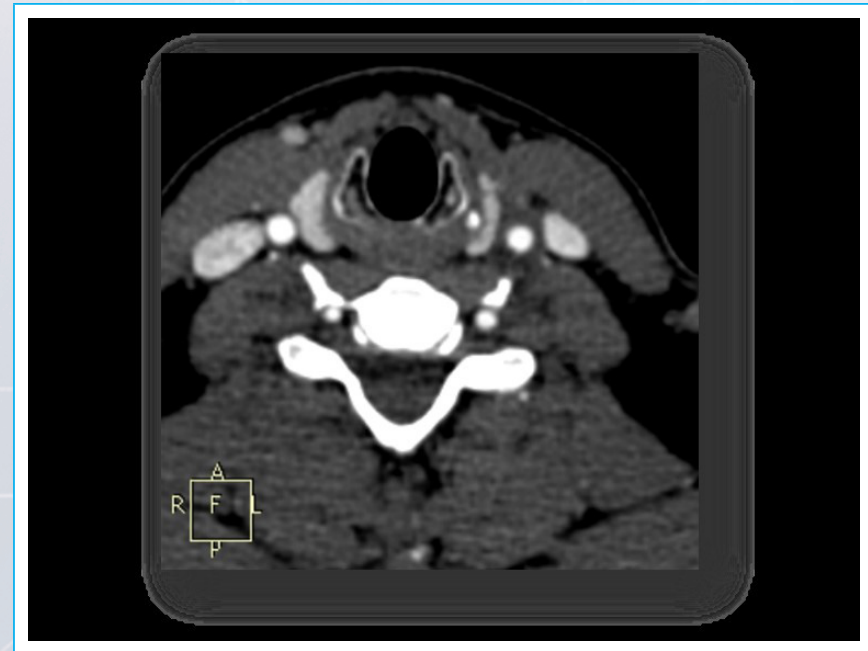

Figura 2A. Angiotomografia multislide de vasos de cuello: Presentó en tercio medio y distal de la arteria carótida primitiva izquierda un engrosamiento parietal concéntrico iso/hipodenso con obliteración del plano graso perivascular y discreta disminución de la luz vascular, imágenes compatibles con hematoma intramural en evolución de curso subagudo.

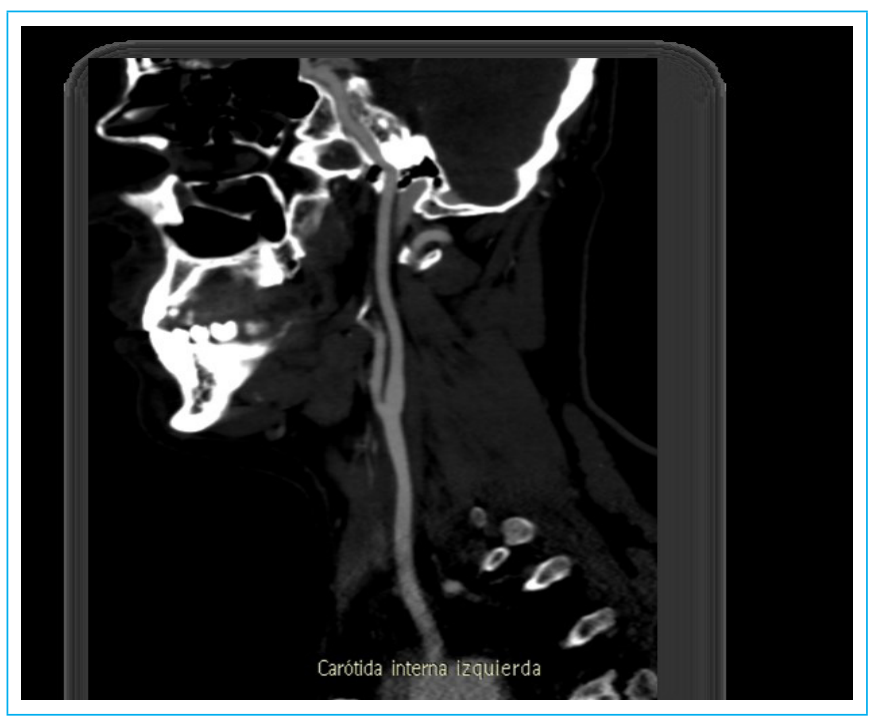

Figura 2B. Angiotomografia multislide de vasos de cuello: Presentó en tercio medio y distal de la arteria carótida primitiva izquierda un engrosamiento parietal concéntrico iso/hipodenso con obliteración de plano graso perivascular y discreta disminución de la luz vascular, imágenes compatibles con hematoma intramural en evolución de curso subagudo.

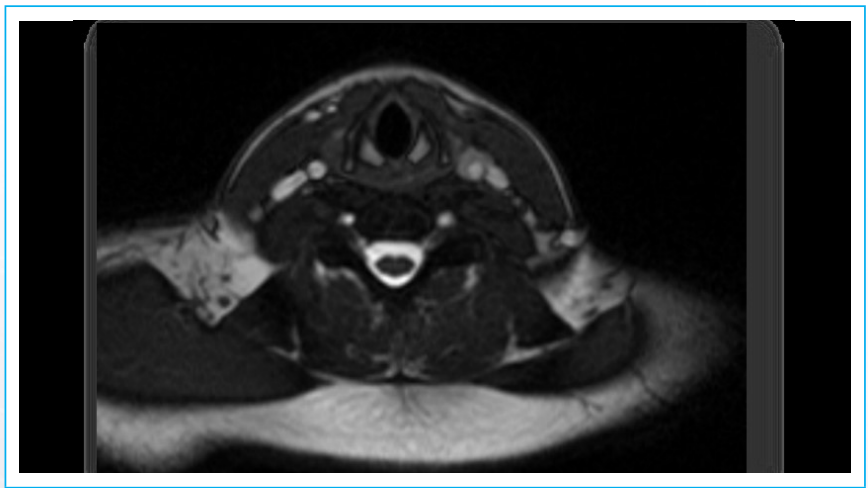

Figura 3. Angioresonancia de vasos de Cuello: se observó imagen parietal en semiluna con señal hiperintensa en secuencia T2 compatible con hematoma intramural en evolución de curso subagudo.

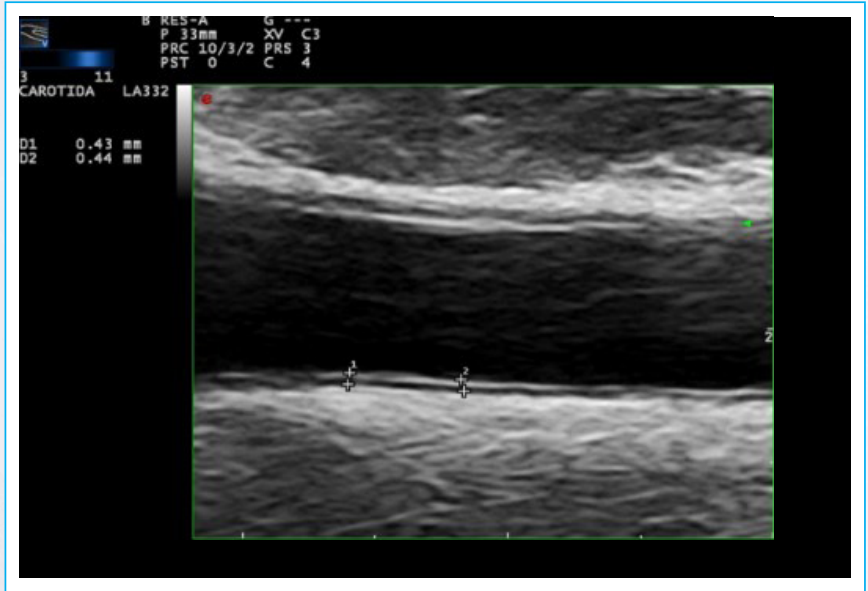

Figura 4A. Doppler Arterial control de Vasos de Cuello: Resolución del hematoma con evidencia de pared arterial de espesor normal. 


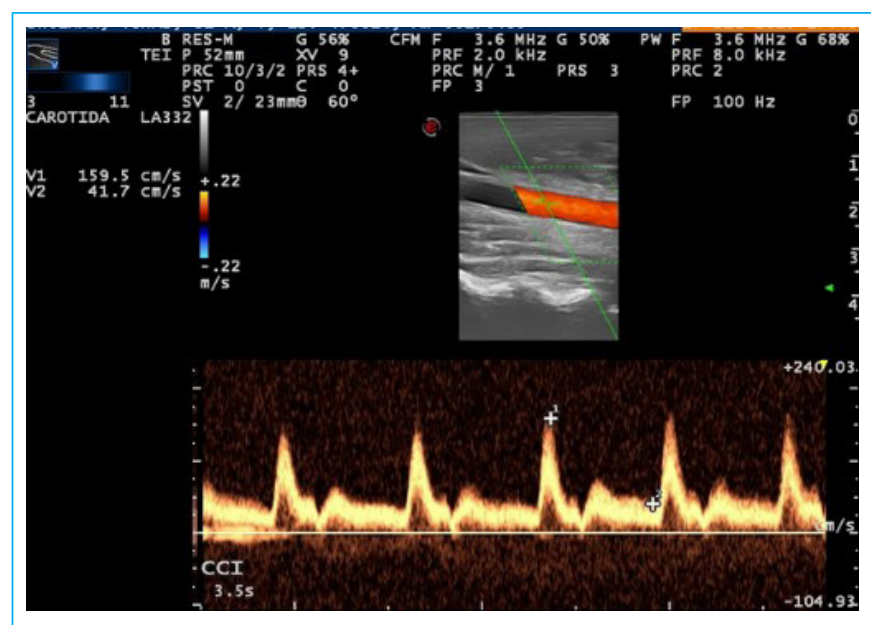

Figura 4B. Flujo arterial normal con Doppler en el estudio de control.

\section{Discusión}

El hematoma intramural puede aparecer como consecuencia de hemorragia localizada en la capa vascular sin evidencia de un desgarro de la íntima; y suceder por lesión de los vasa vasorum. La disección de la arteria carótida suele ser por extensión de disección del arco aórtico, espontánea, y, rara vez, por traumatismo no violento (como el movimiento rápido del cuello).

La población de pacientes con lesión traumática en carótida es joven (menos de 50 años) y 1:3 son hipertensos como factor predisponente. Los síntomas van desde dolor cervical y facial hasta síntomas secundarios a isquemia cerebral. El $70 \%$ se resuelven con mínimo o nulo déficit neurológico, 25\% presentan secuelas graves y $5 \%$ fallecen. Se sabe que la retracción del trombo ya sea espontánea o por tratamiento antitrombótico puede eliminar la estenosis. El DAVC de cuello es de utilidad para realizar el diagnóstico de manera rápida en la sala de emergencias como en este caso y junto con los datos de Angiotomografía se pudo conocer la localización, extensión de la lesión y la determinación de ausencia de complicaciones asociadas. La valoración ampliada de la lesión mediante Angioresonancia ayudó a caracterizar la lesión. Se eligió como método de imagen de seguimiento ambulatorio el DAVC por ser un método confiable para el tipo de lesión, accesible y sin la explosión a la radiación.

\section{Conclusión}

El estudio de DAVC fue de utilidad para realizar el diagnóstico de manera rápida en la sala de emergencias. A través de los datos brindados por el resto de los diferentes métodos de imágenes utilizados pudimos conocer la localización y extensión de la lesión como así también determinar la ausencia de complicaciones asociadas.

De este caso destacamos el aprendizaje de una patología poco prevalente, la importancia de la sospecha clínica y el rol de las imágenes en el diagnóstico y en el seguimiento.

\section{Ideas para recordar}

- La sospecha clínica ayuda a la búsqueda de lesión traumática carotídea mediante una técnica accesible y de bajo costo como es el DAVC.

- Los diferentes métodos de imagen, bien seleccionados, brindan información suficiente para guiar el tratamiento y el seguimiento del paciente.

\section{Bibliografía}

1. "Signo de la Media Luna" en la disección carotídea por angiorresonancia. Sonia Hidalgo. Revista Argentina de Radiología. Vol 3. Num. 1.2009.

2. Disección traumática de la arteria carótida interna por el cinturón de seguridad: descripción de dos casos. M. López-Sánchez. Med. Intensiva. 2009;33(7):353-357.

3. Causes of Misinterpretation of Cross-Sectional Imaging Studies for Dissection of the Craniocervical Arteries. James M. Provenzale. AJR 2011; 196:45-52.

4. Huang Y, Hui PJ, Ding YF, Yan YY, Liu M, Kong LJ, Hu CH, Fang Q. [Analysis of factors related to recanalization of intramural hematoma-type carotid artery dissection]. Zhonghua Yi Xue Za Zhi. 2020 Sep 8;100(33):2612-2617.

5. Hakimi R, Sivakumar S. Imaging of Carotid Dissection. Curr Pain Headache Rep. 2019 Jan 19;23(1):2. 